Article

\title{
Versatile Layer-By-Layer Highly Stable Multilayer Films: Study of the Loading and Release of FITC-Labeled Short Peptide in the Drug Delivery Field
}

\author{
Kun Nie ${ }^{1}$, Xiang Yu ${ }^{1, *}$, Navnita Kumar ${ }^{2}$ and Yihe Zhang ${ }^{1, *}$ \\ 1 Beijing Key Laboratory of Materials Utilization of Nonmetallic Minerals and Solid Wastes, \\ National Laboratory of Mineral Materials, School of Materials Science and Technology, \\ China University of Geosciences (Beijing), Beijing 100083, China; nk@cugb.edu.cn \\ 2 Department of Chemistry and Biochemistry, University of California, Los Angeles, CA 90095, USA; \\ navnitakumar77@gmail.com \\ * Correspondence: yuxiang@cugb.edu.cn (X.Y.); zyh@cugb.edu.cn (Y.Z.); Tel.: +86-189-1180-7048 (X.Y.)
}

Received: 7 March 2019; Accepted: 11 April 2019; Published: 12 April 2019

\begin{abstract}
A viable short FITC-peptide immobilization is the most essential step in the fabrication of multilayer films based on FITC-peptide. These functional multilayer films have potential applications in drug delivery, medical therapy, and so forth. These FITC-peptides films needed to be handled with a lot of care and precision due to their sensitive nature. In this study, a general immobilization method is reported for the purpose of stabilizing various kinds of peptides at the interfacial regions. Utilizing Mesoporous silica nanoparticles can help in the preservation of these FITC-peptides by embedding themselves into these covalently cross-linked multilayers. This basic outlook of the multilayer films is potent enough and could be reused as a positive substrate. The spatio-temporal retention property of peptides can be modulated by varying the number of capping layers. The release speed of guest molecules such as tyrosine within FITC-peptide or/and adamantane (Ad)-in short peptides could also be fine-tuned by the specific arrangements of the multilayers of mesoporous silica nanoparticles (MSNs) and hyaluronic acid- cyclodextrin (HA-CD) multilayer films.
\end{abstract}

Keywords: mesoporous silica; layer-by-layer; FITC-peptide; hyaluronic acid; multilayer film; host-guest interaction

\section{Introduction}

Layer-by-layer self-assembly technology is a useful method to prepare multilayer films with a thickness which can be controlled even down to the nanoscale [1-5], and is among one of the most widely used techniques to weave the organic-inorganic multilayer films together [6-10]. Mesoporous silica nanoparticles (MSNs) have been widely used in adsorption and drug delivery due to their unique pore structure, large specific surface area and good biocompatibility [11]. Some of these can directly act as catalysts as well because the ordered mesoporous material can accelerate the diffusion rate of the product. The selectivity is $100 \%$ and the conversion rate is up to $90 \%$. Due to the flexibility of the structure and the narrow pore distribution, the doping of metal oxide and other complexes to these ordered mesoporous material matrix makes them better catalysts. Biological macromolecules, such as enzymes, proteins, nucleic acids, etc., have molecular sizes less than $10 \mathrm{~nm}$, while viruses have sizes around $30 \mathrm{~nm}$. However, the ordered mesoporous materials have quite a range of pore sizes between 2 and $50 \mathrm{~nm}$. Due to the non-toxicity of these MSNs, they play an important role in the decomposition and fixation of enzymes, proteins and other substances. The mesoporous silica used for a particular 
function needs to be of a particle size, otherwise it will have an adverse effect [11-13]. A lot of research has been done in the area of multilayer films conjoining polymer and inorganic nanoparticles [14-16], and this can be attributed to the variable functionalities from the organic and inorganic parts of multilayer films [17-20]. The multilayer films which incorporate different inorganic parts can generally be prepared either by forming a covalent cross-link or by utilizing the non-covalent interactions between the polymer and the inorganic parts [21-25]. According to the literature, under ultraviolet irradiation, poly (allylamine hydrochloride) (PAH) and 4,4'-diazostilbene-2,2'-disulfonic acid disodium salt (DAS) can form covalent cross-linked layers in situ [26]. Non-covalent multilayer films have been obtained by using different kinds of supramolecular interactions [27-29], electrostatic interactions [30], hydrophobic interactions [29], host-guest interactions [30-32] and so on and so forth.

The knowledge of diffusion mechanism of fluorescent agent in these multilayers is very important and can provide a deeper perspective into the molecular interaction in organisms, soft material systems, and various advanced functional films [33-35]. Due to their good absorptivity, water solubility, and fluorescence quantum yield, Fluorescein derivatives, especially Fluorescein Isothiocyanate (FITC) have become the most popular fluorescent reagents in this field. Owing to their wide fluorescence emission range, their good performance on photo-bleaching and fluorescence quenching on conjugation to biopolymers, the scope of the application can be widened for FITC-based dyes and their conjugates [36].

Hyaluronic acid (HA) consists of repeatable disaccharides of the $\beta$-glucuronic acid and $\mathrm{N}$-acetyl-d-glucosamine [37]. Hyaluronic gel is found in synovial fluid and is the main component of a glycosaminoglycan superstructure complex which is associated with different polysaccharides such as the chondroitin sulfate [38]. Hyaluronic acid can anchor to the surface of the cell by attaching itself to the cell surface receptors. HA is an upcoming drug delivery molecule for soft tissue repair and regeneration [39]. Studies to control the host-guest interaction within supramolecular structures are gradually rising because of their potential application as stimuli-responsive hydrogels, nanoparticles, smart biosensor devices and so on [40,41].

Amino-betacyclodextrin (CD) is a member of cyclic oligosaccharides and consists of the lipophilic central cavity and a hydrophilic outer surface [42,43]. Amino-betacyclodextrin has a large structure with a many hydrogen donors and acceptor groups. However, these groups are impermeable to the lipophilic films, making them difficult to use as a drug delivery vehicle. To enhance aqueous solubility of those poorly soluble drugs and to also raise their bioavailability, cyclodextrin has been utilized as a complexing agent [44]. CD can be grafted onto HA by chemical synthesis, and then the properties of both the moieties in the complex can be utilized. The grafting rate can be measured by ${ }^{1} \mathrm{H}$ NMR [45]. In addition, there is supramolecular hydrophobic host-guest interaction between adamantine (Ad) and cyclodextrin (CD) [46]. Peptides with Ad can be used as targets to study the effect of host-guest interactions in molecular diffusion. At present, there are many reported articles on the host-guest inclusion phenomena that delays the release of peptides [47].

In this paper, we have explored a new method to construct multilayer film materials that effectively preserves different kinds of short peptides. Mesoporous silica serves as a short peptide-container and functional multilayers were embedded in these via electrostatic interactions. Because of the exquisite film structure, the magnitude of the supramolecular interactions within the multilayer films can be modulated. The release curves of the short peptides vary with the number of laminated multilayers. The supramolecular force-delayed molecular release was taken as an example to further demonstrate the functions of the reported peptides immobilization strategy. This technique can be utilized to prepare multilayers which can further be used to control the fabrication of these versatile multilayer films. 


\section{Materials and Methods}

\subsection{Materials and Instruments}

The following chemicals were used without any further treatment: Sodium hyaluronate (HA, 95\%), amino-betacyclodextrin, fluorescein isothiocyanate (FITC, purity > 90), phosphate buffer solution (PBS) and peptides (FITC-RGD \& FITC-RGD-Ad) modified with fluorescein isothiocyanate were provided by Sinopharm Chemical Reagent Beijing Co., Ltd (Beijing, China). Mono-(6-Amino-6-deoxy)-Beta-cyclodextrin was bought from Shandong Binzhou Zhiyuan Biotechnology Co., Ltd (Shandong, China). Peptides (FITC-(SGGYGGS) ${ }_{4}$ \& FITC-(SGGSGGS) 4 ) were bought from LifeTein LLC (Beijing, China). Cetyltrimethylammonium bromide surfactant $\left(\mathrm{CH}_{3}\left(\mathrm{CH}_{2}\right)_{15} \mathrm{~N}\left(\mathrm{CH}_{3}\right)_{3} \mathrm{Br}, \mathrm{CTAB}\right)$, tetraethoxysilane (TEOS) and Poly(allylamine hydrochloride) (PAH, $\mathrm{Mw}=15,000)$ were purchased from Sigma-Aldrich (St. Louis, MO, USA). 4,4'-diazostilbene-2,2'-disulfonic acid disodium salt (DAS), N-Hydroxy succinimide (NHS) and 1-(3-Dimethylaminopropyl)-3-ethylcarbodiimide hydrochloride (EDC) were purchased from TCI (Tokyo Chemical Industry, Tokyo, Japan). Only deionized water was used for all the syntheses.

UV-vis spectra were obtained using a Hitachi U-3900 spectrophotometer (Hitachi, Tokyo, Japan). The Surface morphologies of multilayer films were characterized using transmission electron microscope (TEM) (TEM, Tecnai T12, Field Electron and Ion Company, FEI, Hillsboro, OR, USA). TEM experiments were carried out on a Titan S/TEM (Field Electron and Ion Company, FEI, Hillsboro, OR, USA) microscope. ${ }^{1} \mathrm{H}$ NMR spectra were obtained on Bruker Avance III 400MHz WB (Bruker, Baden, Switzerland). The Brunauer-Emmett-Teller(BET)-Barret-Joyner-Halenda(BJH) BET-BJH data were obtained from the Autosorb-iQ2 (Quantachrome, Boynton Beach, FL, USA).

\subsection{The Preparation of $H A-\beta-C D$ Gels}

HA-CD gel was prepared according to literature [48]. In a $100 \mathrm{~mL}$ Erlenmeyer flask, $0.3 \mathrm{~g}$ of sodium hyaluronate and $50 \mathrm{~mL}$ of morpholinoethanesulfonic buffer (MES) were added and rapid stirred for $6 \mathrm{~h}$. Subsequently, $0.285 \mathrm{~g}$ of NHS and $0.342 \mathrm{~g}$ of EDC were added into the Erlenmeyer flask. Then the mixture was stirred for another hour. To the mixture, $0.1686 \mathrm{~g}$ of amino cyclodextrin was added, followed by stirring for $24 \mathrm{~h}$. The detailed experimental procedure and the sample codes are listed in Table S1. ${ }^{1} \mathrm{H}$ NMR spectroscopy was used to determine the degree of grafting of HA-CD. The graft ratio was calculated by using the integral area of the ${ }^{1} \mathrm{H}$ NMR spectrum. As shown in Figure $\mathrm{S} 1$, the peak at $5.10 \mathrm{ppm}$ represents the proton of amino $(\mathrm{NH})(5.10 \mathrm{ppm})$ group and its integral area was 0.11 . Therefore, the integral area of each hydrogen atom of the aminocyclodextrin was $0.11 / 7$. Similarly, the peak at $2.05 \mathrm{ppm}$ represents the proton of $\mathrm{CH}_{3}(2.05 \mathrm{ppm})$ group and its integral area was 1.00. Therefore, the integral area of each hydrogen atom of hyaluronic acid was $1 / 3$. Grafting ratio was obtained by dividing the integral area of each hydrogen atom of amino cyclodextrin by the integral area of each hydrogen atom of hyaluronic acid. So, according to the ${ }^{1} \mathrm{H} N \mathrm{NMR}\left(400 \mathrm{MHz}, \mathrm{D}_{2} \mathrm{O}\right)$ data, the grafting rate of $\mathrm{HA}-\mathrm{CD}$ was $4.71 \%$.

\subsection{The Synthesis of Mesoporous Silica Nanoparticles (MSNs)}

MSNs were synthetized according to the literature [49]. In brief, an aqueous solution containing of $2.0 \mathrm{~g} \mathrm{CTAB}, 7.0 \mathrm{~mL} \mathrm{NaOH}\left(2 \mathrm{~mol} \mathrm{~L}^{-1}\right)$ and $\mathrm{H}_{2} \mathrm{O}(480 \mathrm{~g})$ was heated for $30 \mathrm{~min}$ at 80 degrees with rapid stirring. To this solution, $8.31 \mathrm{~g}$ ethyl orthosilicate was added. The white solid appeared within two minutes. The product was further stirred at 80 degrees for two more hours, followed by centrifugation, washing with a lot of ultra-pure water, and drying in vacuum oven for $12 \mathrm{~h}$. The CTAB extraction was carried at 60 -degrees Celsius. This white powder was added to a mixture of ethanol $(120 \mathrm{~mL})$ and concentrated hydrochloric acid $(1.0 \mathrm{~mL})$ and stirred for $8 \mathrm{~h}$ at 60 degrees Celsius. The product was then centrifuged and washed with a lot of water and ethanol, followed by drying under vacuum. The diameter of meso- $\mathrm{SiO}_{2}$ is about $100 \mathrm{~nm}$ as seen in TEM images shown in Figure 1c. 
The surface area of the MSN is $646.715 \mathrm{~m}^{2} \mathrm{~g}^{-1}$ and the pore diameter of the MSN was about $3.4 \mathrm{~nm}$, which was characterized via the BET instrument.

(a)

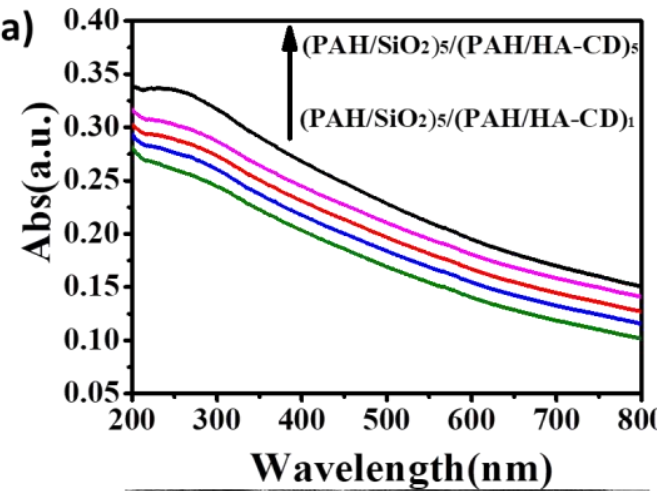

(c)

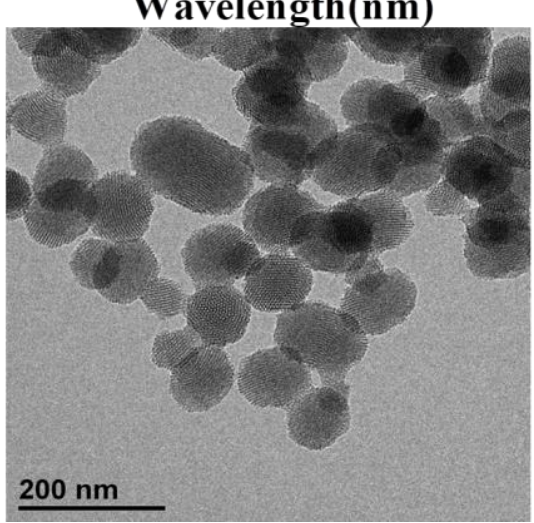

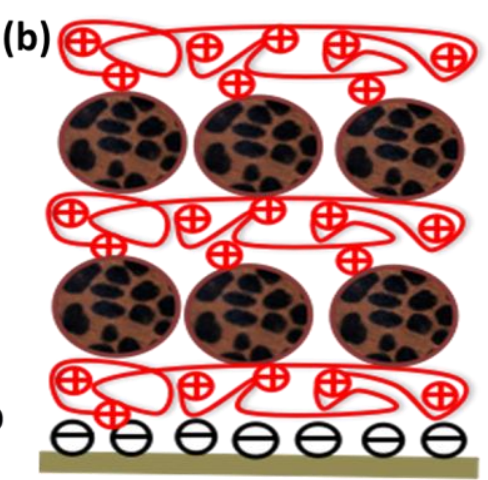

Figure 1. (a) Assembly process followed by UV-vis spectrum of $\left(\mathrm{SiO}_{2} / \mathrm{PAH}\right)_{5} /(\mathrm{PAH} / \mathrm{HA}-\mathrm{CD})_{5} /(\mathrm{PAH} / \mathrm{DAS})_{5}$ multilayers; (b) Cartoon showing the process of layer-by-layer self-assembly; (c) TEM image of MSNs.

\subsection{Layer-By-Layer Assembly Multilayer}

Quartz slides cleaned by piranha solution (concentrated $\mathrm{H}_{2} \mathrm{SO}_{4} / \mathrm{H}_{2} \mathrm{O}_{2}(\mathrm{v}: \mathrm{v}=7: 3)$ ) for $10 \mathrm{~h}$ were immersed in PAH (aq., $\mathrm{MW}=15,000,1 \mathrm{mg} \mathrm{ml}^{-1}, \mathrm{pH}=9$ ) for $25 \mathrm{~min}$ in a typical layer-by-layer cycle. They were rinsed in ultrapure water and then dried with nitrogen. After that, the slides were dipped into the $\mathrm{SiO}_{2}$ solution for $25 \mathrm{~min}$ and rinsed and dried as before. The cycle was continued until desirable thickness was obtained and the related coating film will be designated as $\left(\mathrm{PAH} / \mathrm{SiO}_{2}\right)_{\mathrm{n}}$. Generally, the LBL film was assembled in $\mathrm{pH}=9$ solution. The substrate was immersed in $\mathrm{PAH}$ (aq., $\mathrm{MW}=15,000$, $1 \mathrm{mg} \mathrm{mL}^{-1}, \mathrm{pH}=9$ ) for $25 \mathrm{~min}$, rinsed in ultrapure water, and then dried with nitrogen. Subsequently, these slides were soaked into the HA-CD $\left(1 \mathrm{mg} \mathrm{mL}^{-1}\right)$ solution for $25 \mathrm{~min}$, rinsed and dried as before so that (PAH/HA-CD) LBL films could be deposited onto the surface of the $\left(\mathrm{PAH} / \mathrm{SiO}_{2}\right)_{\mathrm{n}}$ films. The film should be fixed on the quartz substrate to avoid bending during handling so that the good quality of multilayers on the quartz substrate can be guaranteed.

\subsection{Peptide Loading and Release}

$1 \mathrm{mg}$ of FITC-labeled peptide solution was dissolved in $10 \mathrm{~mL}$ of PBS buffer solution ( $\mathrm{pH}=7.4$ ) in a $20 \mathrm{~mL}$ glass beaker at room temperature. The quartz sheets with the multilayers on the surface were then immersed in the peptide solution for $24 \mathrm{~h}$. The quartz sheets were then removed and the surface was immediately rinsed with deionized water and blown dry with nitrogen. Finally, these quartz sheets were used for release experiments in PBS buffer solution.

\section{Results and Discussions}

The surfaces of PAH and DAS are positively charged. PAH and DAS can form covalent cross-linked layers in situ under ultraviolet irradiation. The versatile multilayer films reported here were built 
by integrating MSN, which act as the storage space of polypeptide of FITC-peptide-Ad and the covalently cross-linking multilayers to increase the stability of the whole system of the multilayer films (Scheme 1). A multilayer film of $\left(\mathrm{PAH} / \mathrm{SiO}_{2}\right)_{5} /(\mathrm{PAH} / \mathrm{HA}-\mathrm{CD})_{5}$ was prepared as illustrated in Figure $1 \mathrm{a}$. The formation of this multilayer was monitored by UV-vis spectroscopy. The cartoon as shown in Figure 1b, displays the process of layer by layer self-assembly between MSN and PAH. The MSN used in the experiment were synthesized in our laboratory. The diameters for these MSNs vary from small to $100 \mathrm{~nm}$ as shown in Figure 1c. The thickness of the cross-section of multilayer films prepared on the silica substrate was about $140 \mathrm{~nm}$ with surface roughness of around $35 \mathrm{~nm}$ (Figure S2). As compared to uncross-linked (PAH/DAS $)_{5}$ films, the stability of the $\left(\mathrm{PAH} / \mathrm{SiO}_{2}\right)_{5}$ multilayer films is not great and could not be enhanced, and the absorbance of the basic solution remains $32.26 \%$ of the original absorbance after the immersion as shown by the UV-vis spectra (Figure 2a,b).

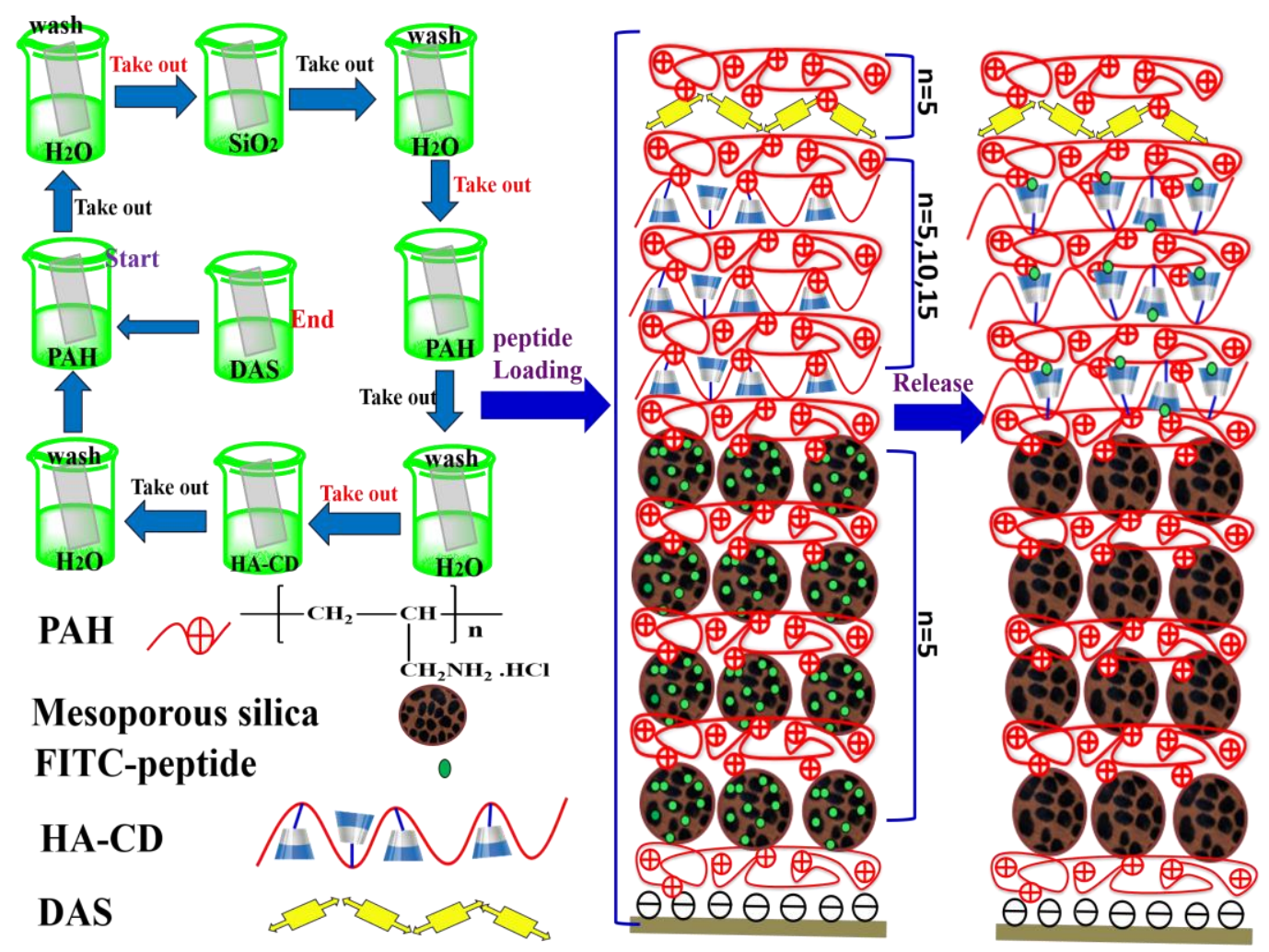

Scheme 1. Description of the loading and release using multilayer film: polymer layers and the mesoporous silica reservoir both play an important role in fabricating functional and stable multilayer films.

UV irradiation was used to enhance the stability of the multilayer films. (PAH/DAS) 5 multilayer films were subsequently prepared by a self-assembly method on the top of the $\left(\mathrm{PAH} / \mathrm{SiO}_{2}\right)_{5} /(\mathrm{PAH} / \mathrm{HA}-\mathrm{CD})_{5}$ multilayers, and cross-link of $(\mathrm{PAH} / \mathrm{DAS})_{5}$ multilayer films was analyzed using UV spectra. The decrease of the absorbance peak at $340 \mathrm{~nm}$ indicates that the DAS decomposes and forms covalent cross-linkages within the (PAH/DAS $)_{5}$ films. The stability of these films can be verified by soaking the cross-linked multilayer films into the basic solution. After the treatment with basic solution for $2 \mathrm{~h}$, the peak absorbance of the multilayer films increased by 94.12\% (Figure 2a).

The result shows that the covalently cross-linked (PAH/DAS) 5 acts as an outermost film which contributes in the enhancement of the stability of the multilayer films within the MSNs. Based on these results, the presence of (PAH/DAS $)_{5}$ multilayer films can enhance the stability of the uncross-linked multilayer films. It was supposed that the nano-net effect resulted in the ability of (PAH/DAS $)_{5}$ multilayer films to improve the stability of the films by incorporating silica underneath. In addition, 
DAS could enter the multilayer films and also enhance the stability of the multilayer films through covalent cross-linking bonding. This effective and facile strategy can play an important role in practical purposes because of its ability in stabilizing different kinds of multilayer films.
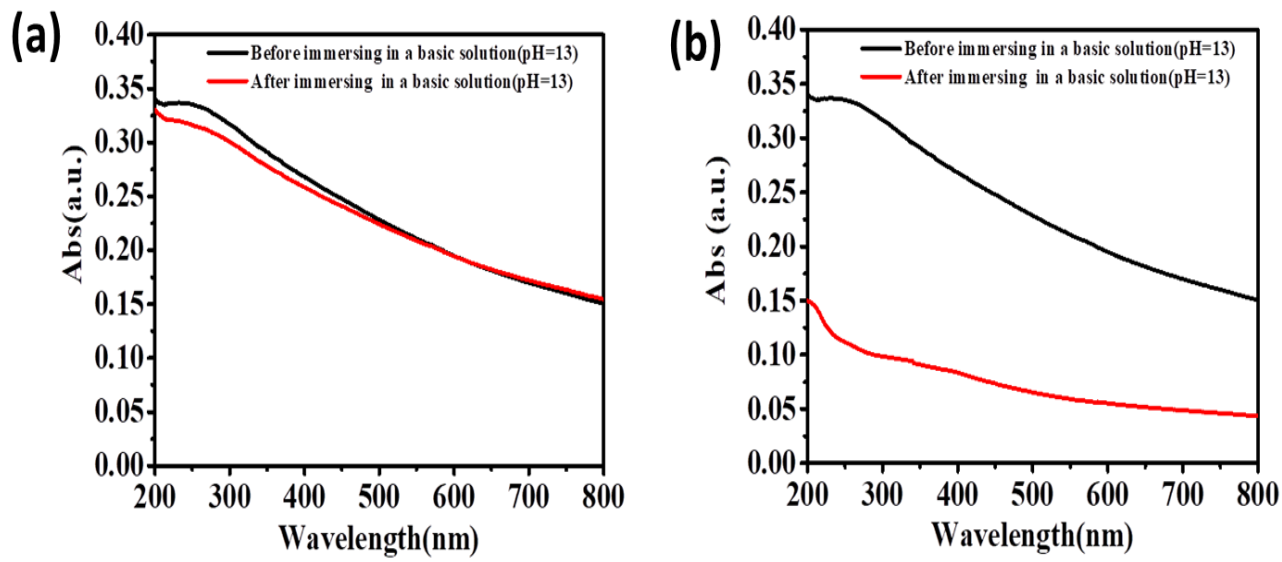

Figure 2. (a) UV-vis spectrum of the cross-linked $\left(\mathrm{SiO}_{2} / \mathrm{PAH}\right)_{5}(\mathrm{PAH} / \mathrm{HA}-\mathrm{CD})_{5}(\mathrm{PAH} / \mathrm{DAS})_{5}$ film before (black) and after (red) immersion in a basic solution ( $\mathrm{pH}=13)$; (b) UV-vis spectrum of the uncross-linked $\left(\mathrm{SiO}_{2} / \mathrm{PAH}\right)_{5} /(\mathrm{PAH} / \mathrm{HA}-\mathrm{CD})_{5} /(\mathrm{PAH} / \mathrm{DAS})_{5}$ film before (black) and after (red) immersion in a basic solution $(\mathrm{pH}=13)$.

In consideration of the above facts, a model multilayer film for the release of FITC-labeled peptides can be employed as a model drug. The host-guest interaction between $C D$ and Ad existed on the three-dimensional scale. The cyclodextrin molecule is hydrophilic from outside and hydrophobic from inside. It indicates that the CD possesses the external hydrophilic surface and the hydrophobic central cavity.

Figure 3 shows the short peptides release profiles from cross-linked multilayer films. Figure 3a clearly shows that the drug release rate of FITC-RGD is faster than the drug release rate of FITC-RGD-Ad. The release curve clearly shows the release time of FITC-RGD from $\left(\mathrm{SiO}_{2} / \mathrm{PAH}\right)_{5} /(\mathrm{PAH} / \mathrm{HA}-\mathrm{CD})_{5} /(\mathrm{PAH} / \mathrm{DAS})_{5}$ is about $180 \mathrm{~min}$ (in the red line) (Figure 3a); however, the release time of FITC-RGD-Ad from $\left(\mathrm{SiO}_{2} / \mathrm{PAH}\right)_{5} /(\mathrm{PAH} / \mathrm{HA}-\mathrm{CD})_{5} /(\mathrm{PAH} / \mathrm{DAS})_{5}$ is about $360 \mathrm{~min}$ (in the black line) (Figure 3a). As shown in Figure 3b, the release time of FITC-RGD and FITC-RGD-Ad is about $360 \mathrm{~min}$ and $480 \mathrm{~min}$, respectively. As shown in Figure S3, ten layers of multilayers were used for experiments to prove that the molecular size had little effect on the release rate. As shown in Figure S3, the release time of both FITC-RGD and FITC-RGD-Ad is about $480 \mathrm{~min}$. As illustrated in Figure 3c, it takes about $480 \mathrm{~min}$ for the release of FITC-RGD, and $720 \mathrm{~min}$ for FITC-RGD-Ad from $\left(\mathrm{SiO}_{2} / \mathrm{PAH}\right)_{5} /(\mathrm{PAH} / \mathrm{HA}-\mathrm{CD})_{5} /(\mathrm{PAH} / \mathrm{DAS})_{5}$ multilayer film. Moreover, it shows that the release profiles are very smooth in Figure 3. Despite the number of multilayers in the film being same, the release speed and release time is different. The delayed effect of the films was caused by the host-guest supramolecular interactions between cyclodextrin and adamantane and also the release process increased with number of the multilayers. In addition, the release time of different kinds of multilayer is summarized in Figure 3d. In the experiment, the controlled variable method was used to study the release of peptide. Figure $4 \mathrm{a}$ is the same as Figure 3a. Compared with the release profiles in Figures 3 and $4 a$, Figure $4 \mathrm{~b}$ clearly shows that the peptide release speed of FITC-RGD is faster than the release speed of FITC-RGD-Ad. The release time of FITC-RGD and FITC-RGD-Ad is about $210 \mathrm{~min}$ and $400 \mathrm{~min}$, respectively. As seen in Figure 4c, the release time of FITC-RGD and FITC-RGD-Ad is $350 \mathrm{~min}$ and $470 \mathrm{~min}$, respectively. Delayed effect of the multilayer films resulted from the host-guest supramolecular interactions, which show an increase in the release process with an increasing number of multilayers. 

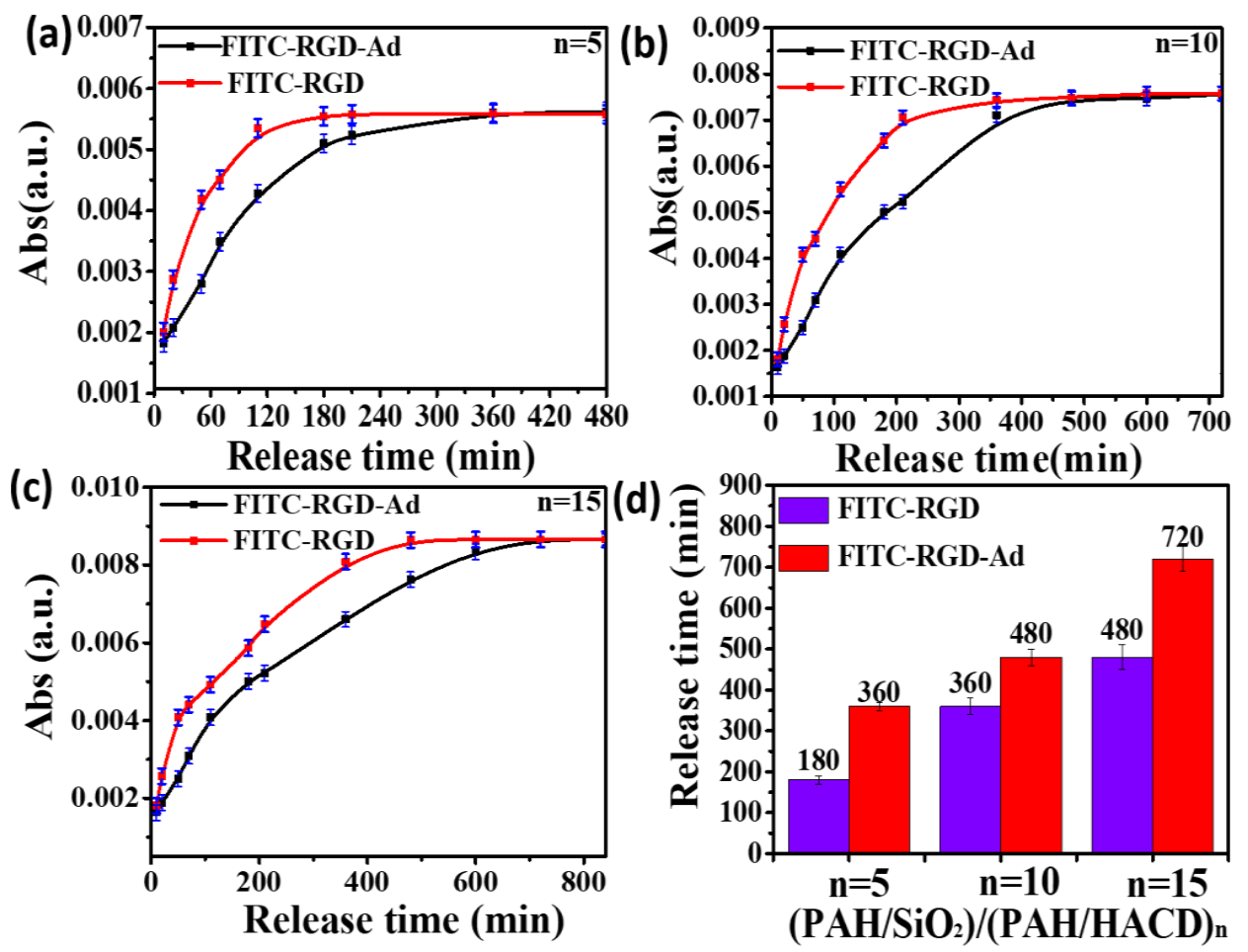

Figure 3. Release profiles of FITC-RGD-Ad and FITC-RGD from the cross-linked (a) $\left(\mathrm{SiO}_{2} / \mathrm{PAH}\right)_{5} /(\mathrm{PAH} / \mathrm{HA}-\mathrm{CD})_{5} /(\mathrm{PAH} / \mathrm{DAS})_{5} ;(\mathbf{b})\left(\mathrm{SiO}_{2} / \mathrm{PAH}\right)_{5} /(\mathrm{PAH} / \mathrm{HA}-\mathrm{CD})_{10} /(\mathrm{PAH} / \mathrm{DAS})_{5}$ and (c) $\left(\mathrm{SiO}_{2} / \mathrm{PAH}\right)_{5} /(\mathrm{PAH} / \mathrm{HA}-\mathrm{CD})_{15} /(\mathrm{PAH} / \mathrm{DAS})_{5}$ multilayer films. (d) the release time of FITC-RGD-Ad and FITC-RGD from different kinds of multilayer films.
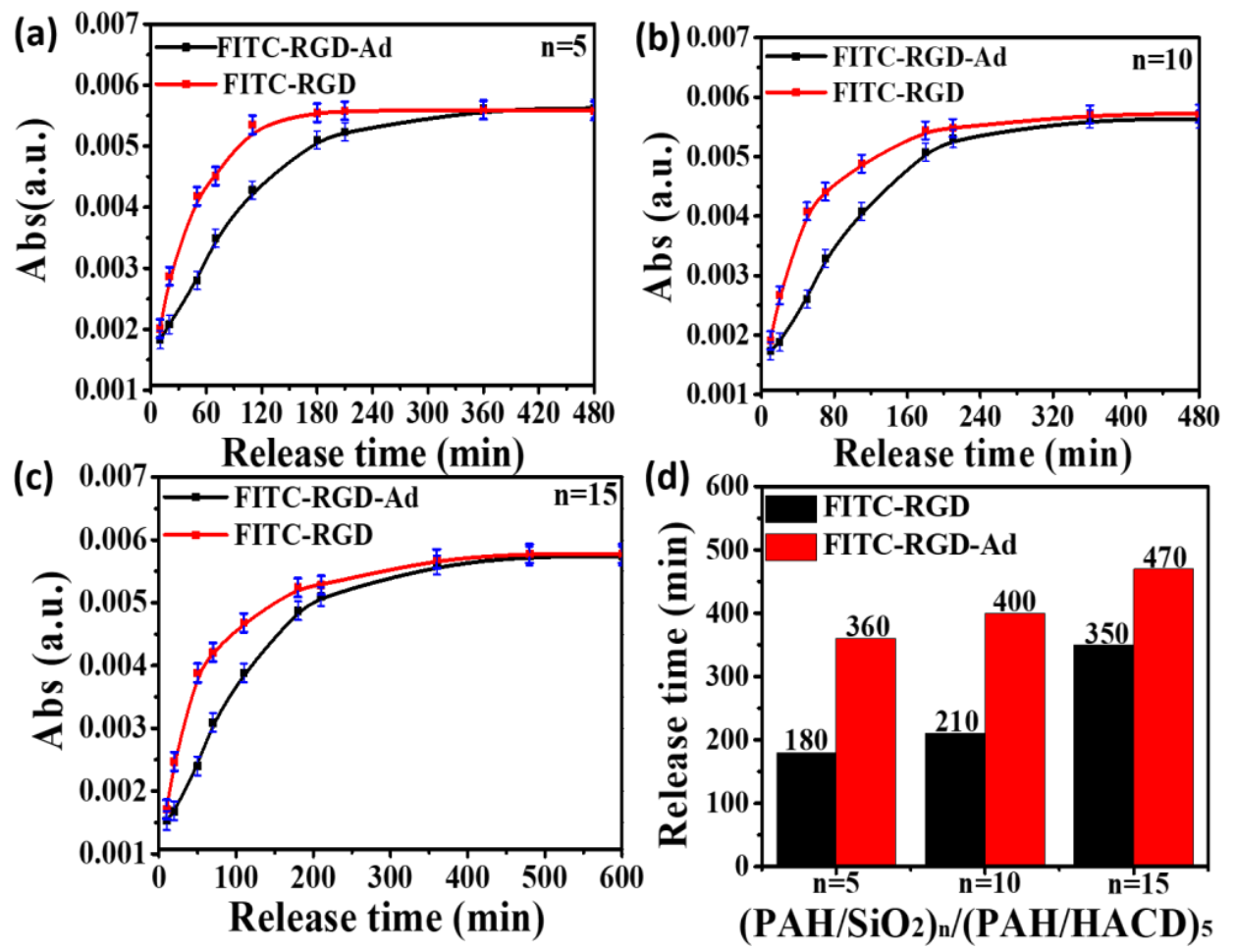

Figure 4. Release profiles of FITC-RGD-Ad and FITC-RGD from the cross-linked (a) $\left(\mathrm{SiO}_{2} / \mathrm{PAH}\right)_{5} /(\mathrm{PAH} / \mathrm{HA}-\mathrm{CD})_{5} /(\mathrm{PAH} / \mathrm{DAS})_{5}$. (b) $\left(\mathrm{SiO}_{2} / \mathrm{PAH}\right)_{10} /(\mathrm{PAH} / \mathrm{HA}-\mathrm{CD})_{5} /(\mathrm{PAH} / \mathrm{DAS})_{5}$ and (c) $\left(\mathrm{SiO}_{2} / \mathrm{PAH}\right)_{15} /(\mathrm{PAH} / \mathrm{HA}-\mathrm{CD})_{5} /(\mathrm{PAH} / \mathrm{DAS})_{5}$ multilayer films. (d) The release time of FITC-RGD-Ad and FITC-RGD from different kinds of multilayer films. 
It is well known that tyrosine $(Y)$ is a hydrophobic amino acid. We infer that host-guest interactions between $C D$ and $Y$ will delay the release speed of Y-based peptide. For proof of concept, different kinds of multilayers were immersed into different solution of peptide, as shown in Figure 5.
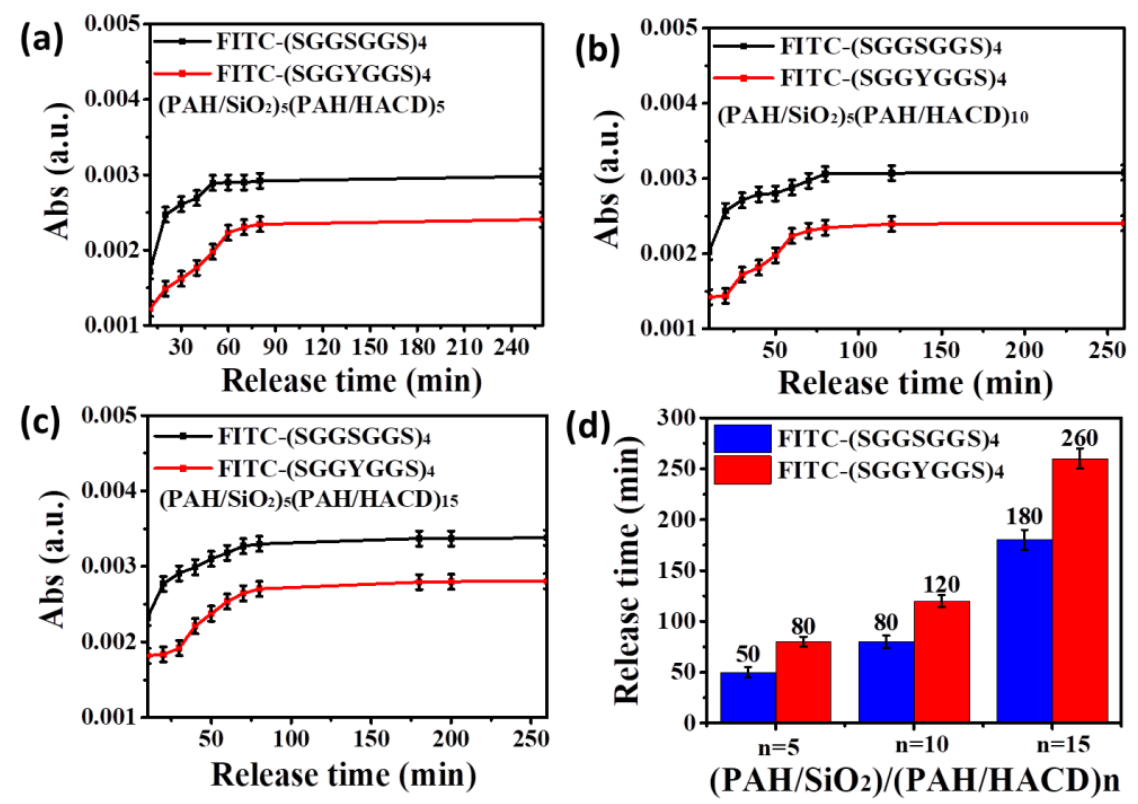

Figure 5. Release profiles of FITC-(SGGSGGS) ${ }_{4}$ or FITC-(SGGYGGS) $)_{4}$ from the cross-linked (a) $\left(\mathrm{SiO}_{2} / \mathrm{PAH}\right)_{5} /(\mathrm{PAH} / \mathrm{HA}-\mathrm{CD})_{5} /(\mathrm{PAH} / \mathrm{DAS})_{5}(\mathbf{b})\left(\mathrm{SiO}_{2} / \mathrm{PAH}\right)_{5} /(\mathrm{PAH} / \mathrm{HA}-\mathrm{CD})_{10} /(\mathrm{PAH} / \mathrm{DAS})_{5}$ and (c) $\left(\mathrm{SiO}_{2} / \mathrm{PAH}\right)_{5} /(\mathrm{PAH} / \mathrm{HA}-\mathrm{CD})_{15} /(\mathrm{PAH} / \mathrm{DAS})_{5}$ multilayer films. (d) The release time of FITC-RGD-Ad and FITC-RGD from different kinds of multilayer films.

As illustrated in Figure 5a, the release time of FITC-(SGGYGGS) 4 from $\left(\mathrm{SiO}_{2} / \mathrm{PAH}\right)_{5}(\mathrm{PAH} / \mathrm{HA}-\mathrm{CD})_{5}(\mathrm{PAH} / \mathrm{DAS})_{5}$ is about $50 \mathrm{~min}$. This is the time taken to obtain saturated release of fluorescent probe. For FITC-(SGGSGGS $)_{4}$ from $\left(\mathrm{SiO}_{2} / \mathrm{PAH}\right)_{5}(\mathrm{PAH} / \mathrm{HA}-\mathrm{CD})_{5}(\mathrm{PAH} / \mathrm{DAS})_{5}$ this release time is 80 mins. As shown in Figure $5 \mathrm{~b}$, the release time of FITC-(SGGYGGS) ${ }_{4}$ from $\left(\mathrm{SiO}_{2} / \mathrm{PAH}\right)_{5}(\mathrm{PAH} / \mathrm{HA}-\mathrm{CD})_{10}(\mathrm{PAH} / \mathrm{DAS})_{5}$ is about $80 \mathrm{~min}$ and around $120 \mathrm{~min}$ for FITC-(SGGYGGS $)_{4}$ from $\left(\mathrm{SiO}_{2} / \mathrm{PAH}\right)_{5}(\mathrm{PAH} / \mathrm{HA}-\mathrm{CD})_{10}(\mathrm{PAH} / \mathrm{DAS})_{5}$. Figure $5 \mathrm{c}$ shows that it takes around $180 \mathrm{~min}$ for the release of FITC-(SGGSGGS) ${ }_{4}$ and $260 \mathrm{~min}$ for FITC-(SGGYGGS) from $\left(\mathrm{SiO}_{2} / \mathrm{PAH}\right)_{5}(\mathrm{PAH} / \mathrm{HA}-\mathrm{CD})_{15}(\mathrm{PAH} / \mathrm{DAS})_{5}$ multilayer films. The more the number of the multilayers in the film, the greater the host-guest interactions. By changing variables and adjusting parameters, it is proved that upon coming in contact with supramolecular forces, host-guest interactions between HA-CD and FITC-(SGGYGGS) ${ }_{4}$ delayed the release speed of fluorescent molecules as shown in Figure 5.

\section{Conclusions}

In this study, a method has been developed which can raise the stability of multilayer films made up of polymer and inorganic nanoparticles. The covalently cross-linked super stratum was formed on outermost layer of the multilayer films so that the structure of multilayers can be stabilized. The super stratum acts as a nano-net which prevents the diffusion of the nanoparticles from the substrate. It is worth mentioning that the super stratum possesses permeability for small molecules like FITC-RGD, FITC-RGD-Ad, FITC-(SGGYGGS) ${ }_{4}$ or FITC-(SGGSGGS) ${ }_{4}$. The difference in permeability of the super stratum towards nanoparticles and small molecules is utilized to synthesize a functional system for drug delivery incorporating mesoporous silica as the molecule reservoir. The construction of functional multilayer films that incorporate inorganic nanoparticles has potential promotional value benefitting from the mild synthesis conditions of the super stratum. 
Supplementary Materials: The following are available online at http://www.mdpi.com/1996-1944/12/8/1206/s1.

Author Contributions: K.N., X.Y., N.K. and Y.Z. conceived and designed the experiments; K.N. conducted the experiments and analyzed the data; K.N. wrote the draft, and K.N., N.K. and X.Y. improved it.

Funding: This research was funded by [National Natural Science Foundation of China] grant number [21303169, 21673209].

Acknowledgments: This work was supported by the NSFC $(21303169,21673209)$ and the National Scholarship Fund of China Scholarship Council (CSC). I am very grateful to Jeffrey I. Zink and Navnita Kumar for helping me to polish and revise the paper. Navnita Kumar is a postdoctoral faculty in the Department of Chemistry and Biochemistry at University of California, Los Angeles (UCLA).

Conflicts of Interest: The authors declare no conflict of interest.

\section{References}

1. Manna, U.; Bharani, S.; Patil, S. Layer-by-Layer Self-Assembly of Modified Hyaluronic Acid/Chitosan Based on Hydrogen Bonding. Biomacromolecules 2009, 10, 2632-2639. [CrossRef]

2. Campbell, M.G.; Liu, Q.; Sanders, A.; Evans, J.S.; Smalyukh, I.I. Preparation of nanocomposite plasmonic films made from cellulose nanocrystals or mesoporous silica decorated with unidirectionally aligned gold nanorods. Materials 2014, 7, 3021-3033. [CrossRef]

3. Nie, K.; An, Q.; Tao, S.Y.; Zhang, Z.P.; Luan, X.L.; Zhang, Q.; Zhang, Y.H. Layer-by-layer reduced graphene oxide (rGO)/gold nanosheets (AuNSs) hybrid films: significantly enhanced photothermal transition effect compared with rGO or AuNSs films. RSC Adv. 2015, 5, 57389-57394. [CrossRef]

4. Anirudhan, T.S.; Vasantha, C.S.; Sasidharan, A.V. Layer-by-layer assembly of hyaluronic acid/carboxymethylchitosan polyelectrolytes on the surface of aminated mesoporous silica for the oral delivery of 5-fluorouracil. Eur. Polym. J. 2017, 93, 572-589. [CrossRef]

5. Wang, D.G.; Sheridan, M.V.; Shan, B.; Famum, B.H.; Marquard, S.L.; Sherman, B.D.; Eberhart, M.S.; Nayak, A.; Dares, C.J.; Das, A.K.; Bullock, R.M.; Meyer, T.J. Layer-by-Layer Molecular Assemblies for Dye-Sensitized Photoelectrosynthesis Cells Prepared by Atomic Layer Deposition. J. Am. Chem. Soc. 2017, 139, 14518-14525. [CrossRef]

6. Kang, E.H.; Bu, T.J.; Jin, P.C.; Sun, J.Q.; Yang, Y.Q.; Shen, J.C. Layer-by-layer deposited organic/inorganic hybrid multilayer films containing noncentrosymmetrically orientated azobenzene chromophores. Langmuir 2007, 23, 7594-7601. [CrossRef]

7. Wang, H.J.; Ishihara, S.; Ariga, K.; Yamauchi, Y. All-Metal Layer-by-Layer Films: Bimetallic Alternate Layers with Accessible Mesopores for Enhanced Electrocatalysis. J. Am. Chem. Soc. 2012, 134, 10819-10821. [CrossRef]

8. Nie, K.; An, Q.; Zhang, Y.H. A functional protein retention and release multilayer with high stability. Nanoscale 2016, 8, 8791-8797. [CrossRef]

9. Xu, Q.W.; Li, X.; Jin, Y.Y.; Sun, L.; Ding, X.X.; Liang, L.; Wang, L.; Nan, K.H.; Ji, J.; Chen, H.; Wang, B.L. Bacterial self-defense antibiotics release from organic-inorganic hybrid multilayer films for long-term anti-adhesion and biofilm inhibition properties. Nanoscale 2017, 9, 19245-19254. [CrossRef]

10. Slowing, I.I.; Vivero-Escoto, J.L.; Wu, C.W.; Lin, V.S.Y. Mesoporous silica nanoparticles as controlled release drug delivery and gene transfection carriers. Adv. Drug Deliv. Rev. 2008, 60, 1278-1288. [CrossRef]

11. Lau, H.H.; Murney, R.; Yakovlev, N.L.; Novoselova, M.V.; Lim, S.H.; Roy, N.; Singh, H.; Sukhorukov, G.B.; Haigh, B.; Kiryukhin, M.V. Protein-tannic acid multilayer films: A multifunctional material for microencapsulation of food-derived bioactives. J. Colloid Interface Sci. 2017, 505, 332-340. [CrossRef]

12. Nguyen, T.T.T.; Belbekhouche, S.; Dubot, P.; Carbonnier, B.; Grande, D. From the functionalization of polyelectrolytes to the development of a versatile approach to the synthesis of polyelectrolyte multilayer films with enhanced stability. J. Mater. Chem. A 2017, 5, 24472-24483. [CrossRef]

13. Jin, W.; Shi, X.Y.; Caruso, F. High activity enzyme microcrystal multilayer films. J. Am. Chem. Soc. 2001, 123, 8121-8122. [CrossRef]

14. Kanazawa, A.; Ikeda, T.; Abe, J. Supramolecular polar thin films built by surfactant liquid crystals: Polarization-tunable multilayer self-assemblies with in-plane ferroelectric ordering of ion-based dipoles. J. Am. Chem. Soc. 2001, 123, 1748-1754. [CrossRef] 
15. Ma, R.Z.; Sasaki, T.; Bando, Y. Layer-by-layer assembled multilayer films of titanate nanotubes, Ag- or Au-loaded nanotubes, and nanotubes/nanosheets with polycations. J. Am. Chem. Soc. 2004, 126, 10382-10388. [CrossRef]

16. Ribeiro, T.; Baleizao, C.; Farinha, J.P.S. Functional films from silica/polymer nanoparticles. Materials 2014, 7, 3881-3900. [CrossRef]

17. Rest, C.; Kandanelli, R.; Fernandez, G. Strategies to create hierarchical self-assembled structures via cooperative non-covalent interactions. Chem. Soc. Rev. 2015, 44, 2543-2572. [CrossRef]

18. Sakata, S.; Inoue, Y.; Ishihara, K. Molecular Interaction Forces Generated during Protein Adsorption to Well-Defined Polymer Brush Surfaces. Langmuir 2015, 31, 3108-3114. [CrossRef]

19. Zhang, D.W.; Tian, J.; Chen, L.; Zhang, L.; Li, Z.T. Dimerization of Conjugated Radical Cations: An Emerging Non-Covalent Interaction for Self-Assembly. Chem. Asian J. 2015, 10, 56-68. [CrossRef]

20. Ma, X.X.; Mei, L.F.; Liu, H.K.; Liao, L.B.; Liu, Y.Q.; Nie, K.; Li, Z.H. Structure and fluorescent properties of Ba3Sc(PO4)(3):Sm3+ red-orange phosphor for n-UV w-LEDs. Chem. Phys. Lett. 2016, 653, 212-215. [CrossRef]

21. Steiner, C.; Gebhardt, J.; Ammon, M.; Yang, Z.C.; Heidenreich, A.; Hammer, N.; Gorling, A.; Kivala, M.; Maier, S. Hierarchical on-surface synthesis and electronic structure of carbonyl-functionalized one- and two-dimensional covalent nanoarchitectures. Nat. Commun. 2017, 8, 14765. [CrossRef]

22. Zhang, X.S.; Jiang, C.; Cheng, M.J.; Zhou, Y.; Zhu, X.Q.; Nie, J.; Zhang, Y.J.; An, Q.; Shi, F. Facile Method for the Fabrication of Robust Polyelectrolyte Multilayers by Post-Photo-Cross-Linking of Azido Groups. Langmuir 2012, 28, 7096-7100. [CrossRef]

23. Nguyen, H.D.; Dang, D.T.; van Dongen, J.L.J.; Brunsveld, L. Protein Dimerization Induced by Supramolecular Interactions with Cucurbit[8]uril. Angew. Chem. Int. Edit. 2010, 49, 895-898. [CrossRef]

24. Boraste, D.R.; Chakraborty, G.; Ray, A.K.; Shankarling, G.S.; Pal, H. Supramolecular host-guest interaction of antibiotic drug ciprofloxacin with cucurbit[7]uril macrocycle: Modulations in photophysical properties and enhanced photostability. J. Photoch. Photobio. Chem. 2018, 358, 26-37. [CrossRef]

25. Conesa-Egea, J.; Redondo, C.D.; Martinez, J.I.; Gomez-Garcia, C.J.; Castillo, O.; Zamora, F.; Amo-Ochoa, P. Supramolecular Interactions Modulating Electrical Conductivity and Nanoprocessing of Copper-Iodine Double-Chain Coordination Polymers. Inorg. Chem. 2018, 57, 7568-7577. [CrossRef]

26. Lee, H.Y.; Park, S.H.; Kim, J.H.; Kim, M.S. Temperature-responsive hydrogels via the electrostatic interaction of amphiphilic diblock copolymers with pendant-ion groups. Polymer Chem. 2017, 8, 6606-6616. [CrossRef]

27. Derbenev, I.N.; Filippov, A.V.; Stace, A.J.; Besley, E. Electrostatic interactions between charged dielectric particles in an electrolyte solution: constant potential boundary conditions. Soft Matter 2018, 14, 5480-5487. [CrossRef]

28. Mishra, A.K.; Weissman, H.; Krieg, E.; Votaw, K.A.; McCullagh, M.; Rybtchinski, B.; Lewis, F.D. Self-Assembly of Perylenediimide-Single-Strand-DNA Conjugates: Employing Hydrophobic Interactions and DNA Base-Pairing To Create a Diverse Structural Space. Chem. Eur. J. 2017, 23, 10328-10337. [CrossRef]

29. Moon, S.; Park, S.O.; Ahn, Y.H.; Kim, H.; Shin, E.; Hong, S.; Lee, Y.; Kwak, S.K.; Park, Y. Distinct hydrophobic-hydrophilic dual interactions occurring in the clathrate hydrates of 3,3-dimethyl-1-butanol with help gases. Chem. Eng. J. 2018, 348, 583-591. [CrossRef]

30. Shumilova, T.A.; Ruffer, T.; Lang, H.; Kataev, E.A. Straightforward Design of Fluorescent Receptors for Sulfate: Study of Non-Covalent Interactions Contributing to Host-Guest Formation. Chem. Eur. J. 2018, 24, 1500-1504. [CrossRef]

31. Xue, F.C.; Wang, Y.Q.; Zhang, Q.X.; Han, S.L.; Zhang, F.Z.; Jin, T.T.; Li, C.W.; Hu, H.Y.; Zhang, J.X. Self-assembly of affinity-controlled nanoparticles via host-guest interactions for drug delivery. Nanoscale 2018, 10, 12364-12377. [CrossRef]

32. Furchner, A.; Kroning, A.; Rauch, S.; Uhlmann, P.; Eichhorn, K.J.; Hinrichs, K. Molecular Interactions and Hydration States of Ultrathin Functional Films at the Solid-Liquid Interface. Anal. Chem. 2017, 89, 3240-3244. [CrossRef]

33. Palao, E.; Sola-Llano, R.; Tabero, A.; Manzano, H.; Agarrabeitia, A.R.; Villanueva, A.; Lopez-Arbeloa, I.; Martinez-Martinez, V.; Ortiz, M.J. Acetylacetonate BODIPY-Biscyclometalated Iridium(III) Complexes: Effective Strategy towards Smarter Fluorescent Photosensitizer Agents. Chem. Eur. J. 2017, 23, 10139-10147. [CrossRef] 
34. Schwenck, J.; Maier, F.C.; Kneilling, M.; Wiehr, S.; Fuchs, K. Non-invasive In Vivo Fluorescence Optical Imaging of Inflammatory MMP Activity Using an Activatable Fluorescent Imaging Agent. Jove-J. Vis. Exp. 2017, 123, e55180. [CrossRef]

35. Luan, L.; Lin, Z.J.; Wu, G.H.; Huang, X.L.; Cai, Z.M.; Chen, X. Encoding electrochemiluminescence using $\mathrm{Ru}(\mathrm{bpy})\left({ }_{3}\right)\left({ }^{2+}\right)$ and fluorescein isothiocyanate co-doped silica nanoparticles. Chem. Commun. 2011, 47, 3963-3965. [CrossRef]

36. Tang, A.M.; Mei, B.; Wang, W.J.; Hu, W.L.; Li, F.; Zhou, J.; Yang, Q.; Cui, H.; Wu, M.; Liang, G.L. FITC-quencher based caspase 3-activatable nanoprobes for effectively sensing caspase 3 in vitro and in cells. Nanoscale 2013, 5, 8963-8967. [CrossRef]

37. Tay, A.; Sohrabi, A.; Poole, K.; Seidlits, S.; Di Carlo, D. A 3D Magnetic Hyaluronic Acid Hydrogel for Magnetomechanical Neuromodulation of Primary Dorsal Root Ganglion Neurons. Adv. Mater. 2018, 30, 1800927. [CrossRef]

38. Souchek, J.J.; Wojtynek, N.E.; Payne, W.M.; Holmes, M.B.; Dutta, S.; Qi, B.W.; Datta, K.; LaGrange, C.A.; Mohs, A.M. Hyaluronic acid formulation of near infrared fluorophores optimizes surgical imaging in a prostate tumor xenograft. Acta Biomater. 2018, 75, 323-333. [CrossRef]

39. Hunt, J.A.; Joshi, H.N.; Stella, V.J.; Topp, E.M. Diffusion and Drug Release in Polymer-Films Prepared from Ester Derivatives of Hyaluronic-Acid. J. Control. Release 1990, 12, 159-169. [CrossRef]

40. Pitarresi, G.; Palumbo, F.S.; Albanese, A.; Fiorica, C.; Picone, P.; Giammona, G. Self-assembled amphiphilic hyaluronic acid graft copolymers for targeted release of antitumoral drug. J. Drug Target 2010, 18, 264-276. [CrossRef]

41. Ramamurthy, V.; Jockusch, S.; Pore, M. Supramolecular Photochemistry in Solution and on Surfaces: Encapsulation and Dynamics of Guest Molecules and Communication between Encapsulated and Free Molecules. Langmuir 2015, 31, 5554-5570. [CrossRef]

42. Mondal, P.; Rath, S.P. Efficient Host-Guest Complexation of a Bisporphyrin Host with Electron Deficient Guests: Synthesis, Structure, and Photoinduced Electron Transfer. Isr. J. Chem. 2016, 56, 144-155. [CrossRef]

43. Kanagaraj, K.; Pitchumani, K. The Aminocyclodextrin/Pd(OAc)(2) Complex as an Efficient Catalyst for the Mizoroki-Heck Cross-Coupling Reaction. Chem. Eur. J. 2013, 19, 14425-14431. [CrossRef]

44. Kaur, N.; Garg, T.; Goyal, A.K.; Rath, G. Formulation, optimization and evaluation of curcumin- $\beta$-cyclodextrin-loaded sponge for effective drug delivery in thermal burns chemotherapy. Drug Deliv. 2016, 23, 2245-2254. [CrossRef]

45. Nakahata, M.; Takashima, Y.; Yamaguchi, H.; Harada, A. Redox-responsive self-healing materials formed from host-guest polymers. Nat. Commun. 2011, 2, 511. [CrossRef]

46. Wei, S.J.; Chu, H.M.; Xu, L.S.; Wang, Z.Z.; Huang, Q. Macrocyclic drug conjugates of metronidazole-cyclodextrin for colon-targeted delivery. J. Control. Release 2017, 259, E120-E121. [CrossRef]

47. Parlati, S.; Gobetto, R.; Barolo, C.; Arrais, A.; Buscaino, R.; Medana, C.; Savarino, P. Preparation and application of a beta-cyclodextrin-disperse/reactive dye complex. J. Incl. Phenom. Macrocycl. Chem. 2007, 57, 463-470. [CrossRef]

48. Nie, K.; An, Q.; Zink, J.I.; Yu, X.; Zhang, Y.H. Layer by Layer Mesoporous Silica-Hyaluronic Acid-Cyclodextrin Bifunctional "Lamination": Study of the Application of Fluorescent Probe and Host-Guest Interactions in the Drug Delivery Field. Materials 2018, 11, 1745. [CrossRef]

49. Trebosc, J.; Wiench, J.W.; Huh, S.; Lin, V.S.Y.; Pruski, M. Solid-state NMR study of MCM-41-type mesoporous silica nanoparticles. J. Am. Chem. Soc. 2005, 127, 3057-3068. [CrossRef]

(C) 2019 by the authors. Licensee MDPI, Basel, Switzerland. This article is an open access article distributed under the terms and conditions of the Creative Commons Attribution (CC BY) license (http://creativecommons.org/licenses/by/4.0/). 